\title{
Importance of coronary artery dominance in child. ren to determine coronary artery dilatation
}

Hee Joung Choi, MD

Department of Pediatrics, Keimyung University School of Medicine, Daegu, Korea

Unlike adult heart disease, coronary artery diseases are uncommon in childhood. In Kawasaki disease, the most common cause of coronary artery disease in children, coronary artery system dilatation, rather than stenotic lesions, is important in the acute phase. Thus, the accurate diagnosis of coronary artery dilation based on universal standards is very important.

Coronary artery dilatation is generally determined by: (1) age-specific absolute values or the ratio to the caliber of a surrounding artery and (2) $z$ score methods, which normalize the coronary artery diameter to body surface area (BSA). ${ }^{1)}$ However, these criteria do not consider coronary artery dominance. Because right coronary artery (RCA) dominance is more common in children and adults (right dominance in 80\%-90\% and left dominance in 10\%-20\%), ${ }^{2,3)}$ the reference values of the left coronary artery (LCA) may actually be small in left dominant patients. Additionally, the incidence of the diagnosis of LCA dilatation may be more common in left dominant patients.

However, few reports have focused on coronary artery dominance in childhood. Lee et al. ${ }^{2)}$ reported the importance of coronary artery dominance in determining coronary artery dilatation in pediatric patients. They examined the coronary artery diameter according to coronary dominance pattern and found significant differences in the diametric ratios of the coronary artery to aortic valve annulus, BSA, and abdominal aorta between the left and right dominant patterns. They also showed that the ratio of the RCA to the LCA was higher in cases of right dominance than left dominance. This finding is the same as the result of a previous study in Korea, which reported that the LCA/RCA ratio differed according to coronary artery dominance, i.e., was decreased in right dominance and increased in left dominance.")

The reason for these differences of coronary artery diameter is the difference in coronary blood flow according to coronary artery dominance. ${ }^{5}$ There is higher coronary artery blood flow in the left circumflex artery and lower blood flow in the RCA in cases of left dominance or balanced circulation versus RCA dominance.

Dionne et al. ${ }^{6}$ focused on the impact of coronary artery anatomical dominance in determining Kawasaki disease-induced coronary artery dilatation. They showed that ipsilateral (dominance-related) coronary dilatations were present at disease onset and that these transient ipsilateral dilatations were caused by a physiological response to an increase in oxygen demand of an inflammatory myocardial state.

Lee et al. ${ }^{2)}$ reported on the impact of coronary artery dominance in determining coronary artery dilatation. Thus, to determine coronary artery dilatation, we must consider the patient's coronary dominance pattern and search carefully for the origin of the posterior descending artery during an echocardiographic evaluation. Large-scale investigations of the standard reference of coronary artery diameter that consider coronary artery dominance are needed.
Corresponding author: Hee Joung Choi, MD

Department of Pediatrics, Keimyung University School of Medicine, 56, Dalseong-ro, Jung-gu, Daegu 41931, Korea

Tel: +82-53-250-7524

Fax: +82-53-250-7783

E-mail: joung756@dsmc.or.kr

http://orcid.org/0000-0002-7119-4194

Received: 14 January, 2019

Revised: 1 April, 2019

Accepted: 3 May, 2019
Copyright $(\odot 2019$ by The Korean Pediatric Society

This is an open-access article distributed under the terms of the Creative Commons Attribution NonCommercial License (http://creativecommons.org/ licenses/by-nc/4.0/ which permits unrestricted noncommercial use, distribution, and reproduction in any medium, provided the original work is properly cited. 


\section{Conflicts of interest}

No potential conflicts of interest relevant to this article was reported.

\section{References}

1. McCrindle BW, Rowley AH, Newburger JW, Burns JC, Bolger AF, Gewitz M, et al. Diagnosis, treatment, and long-term management of Kawasaki disease: a scientific statement for health professionals from the American Heart Association. Circulation 2017;135:e927-99.

2. Lee YJ, Park KS, Kil HR. Change of coronary artery indices according to coronary dominance pattern in early childhood. Korean J Pediatr 2018 Nov 22 [Epub]. https://doi.org/10.3345/kjp.2018.07129.

3. Angelini P. Coronary artery anomalies-current clinical issues: definitions, classification, incidence, clinical relevance, and treatment guidelines. Texas Heart Inst J 2002;29:271-8.

4. Choi JY, Yun YS, Noh CI, Choi JU, Kang IS. Dimension of normal coronary arteries determined by cross-sectional echocardiography. Korean J Pediatr 1992;35:1336-42.

5. Sakamoto S, Takahashi S, Coskun AU, Papafaklis MI, Takahashi A, Saito S, et al. Relation of distribution of coronary blood flow volume to coronary artery dominance. Am J Cardiol 2013;111:1420-4.

6. Dionne A, Hanna B, Trinh Tan F, Desjardins L, Lapierre C, Déry J, et al. Importance of anatomical dominance in the evaluation of coronary dilatation in Kawasaki disease. Cardiol Young 2017;27:877-83. 